\title{
In Memoriam: Donald L. Morton, MD (1934-2014): An Icon in Surgical Oncology
}

\author{
Past President, Society of Surgical Oncology (1992-1993) and Associate Editor, Annals \\ of Surgical Oncology (1993-2014)
}

\author{
Charles M. Balch, MD, FACS ${ }^{1}$, Mark S. Roh, $\mathrm{MD}^{2}$, V. Suzanne Klimberg, $\mathrm{MD}^{3}$, and Deborah A. Whippen, $\mathrm{BA}^{4}$ \\ ${ }^{1}$ Division of Surgical Oncology, University of Texas Southwestern Medical Center, Dallas, TX ; ${ }^{2}$ University of Florida \\ Health Cancer Center at Orlando Health, Orlando, FL; ${ }^{3}$ Winthrop P. Rockafeller Cancer Institute, University of Arkansas, \\ Little Rock, AR; ${ }^{4}$ Annals of Surgical Oncology Editorial Office, Orange Park, FL
}

Donald L. Morton, M.D. (Fig. 1), who passed away on 10 January 2014, was a true legend in the field of surgical oncology, as well as a pioneer in the field of immunotherapy. As President-elect and then President of the Society of Surgical Oncology from 1992 to 1993, he was instrumental in the launching the Annals of Surgical Oncology. Dr. Morton was an associate editor of the journal for 20 years, during which time he was a major contributor of many high impact articles. He was also a cancer survivor, and publically described his experience with two separate melanomas and a lengthy battle with lymphoma.

Dr. Morton received the prestigious Heritage Award from the Society of Surgiccal Oncology in 2003 and his professional accomplishments up to that time were nicely described by Past President William C. Wood. ${ }^{1}$ Several years ago, we also described Dr. Morton's extraordinary professional accomplishments in an invited editorial that we have liberally quoted and updated for this article. ${ }^{2}$

Over a half century career, Dr. Donald L. Morton changed our melanoma surgical practice and our oncology management on a global basis. His pioneering clinical research efforts in the development and clinical application of sentinel lymph node biopsy (SLNB) have transformed the surgical management of many solid tumors, particularly melanoma and breast cancer. ${ }^{3,4}$ In these latter two cancers,

(c) Society of Surgical Oncology 2014

Published Online: 17 March 2014

C. M. Balch, MD, FACS

e-mail: balch@asoeditorial.org
SLNB has replaced complete lymphadenectomy for staging the regional nodes, thereby reducing healthcare costs in the United States by about $\$ 3.5$ billion each year. He has also conducted numerous clinical research projects that have shaped our perspective and clinical management of our cancer patients, particularly in the field of melanoma. His pioneering work with intratumoral bacille CalmetteGuerin (BCG) for melanoma represented the first successful clinical application of immunotherapy against a metastatic human cancer. His work with BCG in melanoma metastatic to the bladder also laid a foundation for the use of intravesical BCG in superficial bladder cancer, which became the first US Food and Drug Administration (FDA)approved cancer immunotherapy. ${ }^{5} \mathrm{He}$ was also one of the pioneers for performing limb salvage surgery and pulmonary metastasectomy for soft tissue sarcomas. ${ }^{6}$ Although all of these made significant advances using the instruments of clinical trials, Dr. Morton was also a translational researcher who made fundamental discoveries in the field of tumor immunology and immunotherapy that has stimulated an entire field of inquiry.

When Dr. Morton's scientific journey is examined from the perspective of a surgical investigator, he has few peers. He defined his approach as follows: "Our goal as cancer researchers is to make things better. We identify problems with the status quo, then try to discover better ways to do things." His research has credibility and reproducibility because he rigorously tested his hypotheses using the structure of prospective clinical trials, sophisticated database analyses, and multidisciplinary collaborations. He was an outstanding surgeon, as well as an accomplished oncologist. 


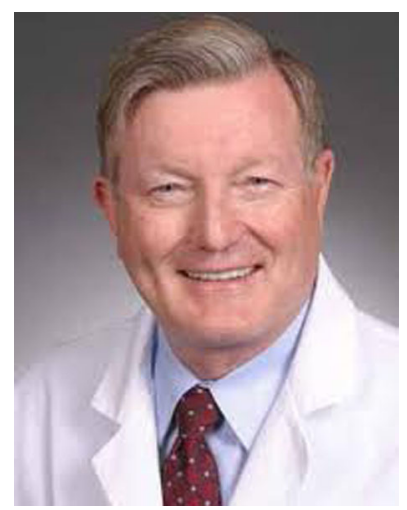

FIG. 1 Dr. Donald L. Morton, MD (1934-2014)

TABLE 1 Top 10 most cited articles published in the Annals of Surgical Oncology by Dr. Donald Morton and colleagues

1. Efficacy of lymphatic mapping, sentinel lymphadenectomy, and selective complete lymph node dissection as a therapeutic procedure for early-stage melanoma

Essner R, Conforti A, Kelley MC, et al. Jul-Aug 1999;6(5):442-9

2. Validation of lymphatic mapping in colorectal cancer: in vivo, ex vivo, and laparoscopic techniques

Wood TF, Saha S, Morton, DL, et al. Mar 2001;8(2):150-7

3. Isolated tumor cells in the sentinel node affect long-term prognosis of patients with melanoma

Scheri RP, Essner R, Turner RR, et al. Oct 2007;14(10):2861-6

4. Will the true sentinel node please stand?

Morton DL, Bostick PJ Jan-Feb 1999;6(1):12-4

5. Does complete, resection of melanoma metastatic to solid intraabdominal organs improve survival?

Wood TF, DiFronzo LA, Rose DM, et al. Sep 2001;8(8):658-62

6. Melanoma patients with positive sentinel nodes who did not undergo completion lymphadenectomy: a multi-institutional study

Wong SL, Morton DL, Thompson JF, et al. Jun 2006;13(6):809-16

7. Prognostic implications of thick ( $>$ or $=4-\mathrm{mm}$ ) melanoma in the era of intraoperative lymphatic mapping and sentinel lymphadenectomy

Essner R, Chung MH, Bleicher R, et al. Oct 2002;9(8):754-61

8. Immune response to polyvalent melanoma cell vaccine in AJCC stage III melanoma: an immunologic survival model

Jones RC, Kelley M, Gupta RK, et al. Sep 1996;3(5):437-45

9. Parotid region lymphatic mapping and sentinel lymphadenectomy for cutaneous melanoma

Ollila DW, Foshag LJ, Essner R, et al. Mar 1999;6(2):150-4

10. Increased incidence of second primary melanoma in patients with a previous cutaneous melanoma

DiFronzo LA, Wanek LA, Elashoff R, et al. Oct-Nov 1999;6(7):705-11

Ordered by most-to-least number of citations; source: ISI Web of Science
His accomplishments are prodigious and are described in more detail elsewhere. ${ }^{7}$ Here are a few in summary:

- Dr. Morton authored over 1,000 publications and received competitive research funding from National Cancer Institute for more than 38 years.

- He trained over 100 fellows, of which $80 \%$ are in leadership roles in academic institutions or major cancer centers.

- He had an uncanny skill in shaping his ideas and visions into successful federal grants. The journal Science placed him at the top of a list of clinical investigators who received the most grant funding from the National Institutes of Health during 2000 (Science; June 15, 2001).

Don was a prodigious writer whose publications covered many different fields. The ISI Web of Science (Thomson Reuters) lists 924 of Dr. Morton's publications (as of January 2014) that have been cited over 35,000 times in the biomedical literature (an average of 38 times per article). More than half of these publications involve the field of melanoma, and these have been cited over 19,000 times. Any of us would be pleased that a publication was cited 50 or 100 times, but Dr. Morton had more than 60 articles that have been cited over 100 times. Indeed, over the past few years, his collective publications have been cited over 1,600 times per year! Examine the diversity of his top 10 "high impact" publications as a lead author or as a coauthor, for which 7 of the 10 articles advanced the field of melanoma (Table 1).

Indeed, in the annals of surgical research, there are very few who have contributed such a wealth of biological and clinical knowledge that Dr. Morton and his dedicated research team have accomplished through the decades, and his legacy will continue to contribute through his impact on international randomized surgical trials, translational research programs, and his trainees.

The story about lymphatic mapping and the sentinel node procedure deserves special mention, for he is the singular pioneer of these techniques that have now been adopted worldwide. His initial studies began in the mid1970s when he published the first report of cutaneous lymphoscintigraphy for identifying potential bidirectional lymphatic drainage to regional lymph node basins in truncal melanoma. ${ }^{8}$ This technique was quickly adopted in nuclear medicine departments. The next issue that he addressed, which was on the regional nodes, was the "first draining lymph node" or sentinel node within a nodal basin as defined precisely by the cutaneous lymphoscintogram. First, through observational clinical studies, and then systematically in a cat model, ${ }^{9}$ he developed and tested the clinical application of the sentinel node technique to improve the staging of melanoma. His first results were 
presented at the Society of Surgical Oncology meeting in 1990. The manuscript describing this methodology was rejected by several "high-impact journals". Undaunted, he persisted until the paper was published in the Archives of Surgery in 1992. ${ }^{3}$ It became a classic article with over 2,400 citations to date! To his credit, he went on to validate this technique through a series of brilliantly designed clinical trials, first at his own institution, and then with two landmark international studies, the Multicenter Selective Lymphadenectomy Trial (MSLT) I and the MSLT II, which are surgical trials on the role of the sentinel node biopsy and therapeutic lymphadenectomy for melanoma. ${ }^{10,11}$ Just as his BCG studies stimulated the entire field of cancer immunotherapy, he facilitated the entire field of SLN staging by organizing a multidisciplinary forum where surgeons, pathologists, nuclear medicine physicians, medical oncologists, and laboratory scientists from around the world could share their findings at biannual meetings of The International Sentinel Node Society, for which he was the founder and first president. ${ }^{12}$ His final major publication occurred right after his death in the New England Journal of Medicine involving the final results of the MSLT 1 sentinel node biopsy. ${ }^{13}$ As reported, the MSLT-1 is a landmark prospective randomized clinical trial that caps a 35-year effort to resolve the controversy surrounding the survival benefit of surgical excision of regional lymph nodes as a component of the initial management patients with primary melanoma. ${ }^{14}$ Spanning two decades, the MSLT-I further demonstrates the staging and prognostic significance of the sentinel node biopsy (SNB) technique for melanomas $\geq 1.2 \mathrm{~mm}$ thick. In the cohort of nodepositive patients with primary melanomas $1.2 \mathrm{~mm}-3.5 \mathrm{~mm}$ thick, the MSLT-I showed a significant melanoma-specific survival advantage for those who had a positive SNB and early regional lymphadenectomy compared to those who had delayed regional lymphadenectomy after regional disease developed after wide excision alone. ${ }^{13}$ The integration of SNB into the management of intermediate- and high-risk primary melanomas has significantly changed the melanoma landscape by clarifying the prognostic heterogeneity of stage I and II melanoma and by unraveling the prognostic heterogeneity of stage III melanoma, This practice-changing trial demonstrates the important role of early identification and surgical removal of regional metastases, both for staging value and for improved survival in defined cohorts of melanoma patients. ${ }^{13,14}$

With Dr. Morton's leadership role as the Associate Editor, and with contributions as a reviewer and author, the Annals of Surgical Oncology has emerged as the most cited surgical oncology journal published in the world and has been adopted as a venue for communicating new knowledge by and for surgeons all over the world. The success of the journal is dependent upon the peer review process from over 2,500 content experts selected as reviewers of submitted manuscripts to the Annals of Surgical Oncology (ASO) in 2013. In this vital area, Dr. Morton volunteered many hours of time to review journal manuscripts. Over the 20-year history of the Annals of Surgical Oncology, Dr. Morton was a major contributor to the journal and he published 68 articles on a wide range of topics. Collectively, these articles were cited 1,100 times (an average of 16 citations per article). We have listed in Table 1 the top 10 of his most cited articles in the Annals of Surgical Oncology. The readership of the journal is now located in almost every country in the world with almost 500,000 full text downloads in 2013 across 36 countries. Dr. Morton's work is highly read, for we can track from 2008-2013, more than 10,700 electronic downloads of articles that he has published.

Donald L. Morton was an inspiration to us all. His prowess as a clinical surgeon has saved the lives of many patients; his research has contributed to our fund of knowledge that we use every day around the world in our own clinical practices; his training of a cadre of surgeons and investigators, who in turn became leaders in their field; and his influence on us all in the field of surgical oncology, with his professional standards, strategies, and approaches, we have all emulated in our own professional lives.

Donald Morton was truly a legend in surgical oncology, an icon as a surgical investigator, a pioneer in melanoma, a valued mentor, an authentic role model, and a cherished friend to many of us around the world. Though he led a busy professional life, he was also a devoted husband to his wife Lorraine and his family. His presence will be missed, but his impact on myriads will live on.

\section{REFERENCES}

1. Wood WC. Honoring Donald M. Morton, MD: Society of Surgical Oncology President, 1992-1993. Ann Surg Oncol. 2003;10:1125-7.

2. Balch CM. Donald L. Morton, MD ... a living legend in surgical oncology. J Surg Oncol. 2011;104:338-40.

3. Morton DL, Wen DR, Wong JH, et al. Technical details of intraoperative lymphatic mapping for early stage melanoma. Arch Surg. 1992;127:392-9.

4. Giuliano AE, Kirgan DM, Guenther JM, Morton DL. Lymphatic mapping and sentinel lymphadenectomy for breast cancer. Ann Surg. 1994;220:391-8.

5. Silverstein MJ, deKernion JD, Morton DL. Malignant-melanoma metastatic to bladder - regression following intratumor injection of BCG vaccine. JAMA. 1974;229:688.

6. Morton DL, Eilber FR, Townsend CM, et al. Limb salvage from a multidisciplinary treatment approach for skeletal and soft-tissue sarcomas of extremity. Ann Surg. 1976;184:268-78.

7. Wood WC. Honoring Donald L. Morton, MD: Society of Surgical Oncology President. Ann Surg Oncol. 2003;10:1125-7.

8. Fee HJ, Robinson DS, Sample WF, Graham LS, Holmes EC, Morton DL. The Determination of lymph shed by colloidal gold 
scanning patients with malignant melanoma: a preliminary study. Surgery. 1978;84:626-2.

9. Wong JH, Cagle LA, Morton DL. Lymphatic drainage of skin to a sentinel lymph node in a feline model. Ann Surg. 1991;214: 637-41.

10. Morton DL, Cochran AJ, Thompson JF, et al. Sentinel node biopsy for early-stage melanoma: accuracy and morbidity in MSLT-I, an international multicenter trial. Ann Surg. 2005;242: 302-11.

11. Morton DL, Thompson JF, Cochran AJ, et al. Sentinel-node biopsy or nodal observation in melanoma. N Engl J Med. 2006; 355:1307-17
12. Morton DL. Sentinel node mapping and an international sentinel node society: current issues and future directions. Ann Surg Oncol. 2004;11:137S-43S.

13. Morton DL, Thompson JF, Cochran AJ, et al. Final trial report of sentinel-node biopsy versus nodal observation in melanoma. $N$ Engl J Med. 2014;370:599-609.

14. Balch CM and Gershenwald JE. Clinical value of the sentinelnode biopsy in primary cutaneous melanoma. $N$ Engl $\mathrm{J} \mathrm{Med}$. 2014;370:663-4. 